\title{
Homogenization and analysis of an expanded long-term monthly rainfall network for the Island of Ireland (1850-2010)
}

\author{
S. Noone, ${ }^{a}$ C. Murphy, ${ }^{\text {a* }}$ J. Coll, ${ }^{\text {a }}$ T. Matthews, ${ }^{\mathrm{b}}$ D. Mullan, ${ }^{\mathrm{c}}$ R. L. Wilby ${ }^{\mathrm{d}}$ and S. Walsh ${ }^{\mathrm{e}}$ \\ a Irish Climate Analysis and Research UnitS (ICARUS), Department of Geography, National University of Ireland Maynooth, Ireland \\ ${ }^{\mathrm{b}}$ School of Natural Sciences and Psychology, Liverpool John Moores University, UK \\ c School of Geography, Archaeology and Palaeoecology, Queen's University Belfast, UK \\ ${ }^{\mathrm{d}}$ Department of Geography, Loughborough University, UK

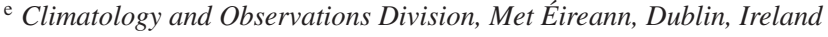

\begin{abstract}
Long-term precipitation series are critical for understanding emerging changes to the hydrological cycle. To this end we construct a homogenized Island of Ireland Precipitation (IIP) network comprising 25 stations and a composite series covering the period 1850-2010, providing the second-longest regional precipitation archive in the British-Irish Isles. We expand the existing catalogue of long-term precipitation records for the island by recovering archived data for an additional eight stations. Following bridging and updating of stations HOMogenisation softwarE in R (HOMER) homogenization software is used to detect breaks using pairwise and joint detection. A total of 25 breakpoints are detected across 14 stations, and the majority (20) are corroborated by metadata. Assessment of variability and change in homogenized and extended precipitation records reveal positive (winter) and negative (summer) trends. Trends in records covering the typical period of digitization (1941 onwards) are not always representative of longer records. Furthermore, trends in post-homogenization series change magnitude and even direction at some stations. While cautionary flags are raised for some series, confidence in the derived network is high given attention paid to metadata, coherence of behaviour across the network and consistency of findings with other long-term climatic series such as England and Wales precipitation. As far as we are aware, this work represents the first application of HOMER to a long-term precipitation network and bodes well for use in other regions. It is expected that the homogenized IIP network will find wider utility in benchmarking and supporting climate services across the Island of Ireland, a sentinel location in the North Atlantic.
\end{abstract}

KEY WORDS HOMER; homogenization; Island of Ireland; metadata; precipitation; trend

Received 13 July 2015; Revised 2 September 2015; Accepted 4 September 2015

\section{Introduction}

Long precipitation series help contextualize recent climate variability, identify emerging trends, ground-truth climate models and understand impacts on sectors such as agriculture, water resources and flood management (e.g. Jones et al., 2006; Wilby and Quinn, 2013). High-quality observations prior to 1900 are relatively rare (Jones, 1984; Burt et al., 1998, 2014; Barker et al., 2004; De Jongh et al., 2006; Jones et al., 2006; Wilby, 2006). However, several European studies have employed long-term precipitation records to detect change and contextualize shorter series (Auer et al., 2005; De Jongh et al., 2006; Moberg et al., 2006).

The pioneering work of Tabony (1980) is of particular significance to the British-Irish Isles (BI). This composite of long-term monthly rainfall records was based on 185 sites across Europe with data collated from various

\footnotetext{
* Correspondence to: C. Murphy, Irish Climate Analysis and Research UnitS (ICARUS), Department of Geography, National University of Ireland Maynooth, Maynooth, Ireland. E-mail: conor.murphy@nuim.ie
}

National Meteorological Services. Continuous, long-term precipitation series were then constructed using combinations of overlapping records adjusted by correction factors. Briffa (1984) also produced long-term composite rainfall records including four sites in Ireland using methods similar to Tabony (1980). Others have subsequently updated the work of Tabony (1980) and Briffa (1984) (e.g. Jones, 1983; Gregory et al., 1991; Jones and Conway, 1997; and Burt et al., 2014). Additional long-term regional rainfall reconstructions include the work of Barker et al. (2004) who constructed a 200-year monthly precipitation series for the English Lake District through bridging between non-continuous station records, and Todd et al. (2014) who produced an extension of composite rainfall series for Carlisle (northwest England) to homogenize station records back to 1757 .

Analysis of these records has yielded important insights. For example, Burt et al. (1998) used precipitation records from 1880 to 1997 to show that the most notable period of drought occurred in 1991 together with changes in the seasonality of rainfall (winter/summer contrast becoming 
more extreme in decades prior to 1997). Burt et al. (2014) later employed long-term precipitation records for the BI to analyse and contextualize very high monthly rainfall totals in the 1870s relative to recent rainfall extremes.

In Ireland most precipitation analyses have been restricted to relatively short records (post-1940s) due to a lack of suitable quality controlled or homogenized long-term datasets (e.g. Kiely, 1999; Sheridan, 2001; Wang et al., 2006; Leahy and Kiely, 2011; Dwyer, 2012). A few studies have taken a longer term view; McElwain and Sweeney (2007) assessed monthly data at Birr and Malin Head from 1890 to 2003 and found significant increases in annual totals at Malin Head with no trends present at Birr (McElwain and Sweeney, 2007). Jones and Conway (1997) calculated area average monthly precipitation for the whole of Ireland for the period 1840-1995 using station observations and reconstructions from tree rings. They found that all regions have seen increases in winter precipitation and decreases in summer over the period. Butler et al. (1998) used records for Armagh observatory, Northern Ireland, dating back to 1838 to show summers have become drier since the 1960s.

A homogeneous climate time series is defined as one where variability is only caused by changes in weather or climate (Freitas et al., 2013). Most decade to century-scale time series of atmospheric data have been adversely impacted by inhomogeneity caused by, for example, changes in instrumentation or observer practices, station moves, or changes in the local environment (e.g. urbanization). Some of these factors can cause abrupt shifts; others gradual changes over time, which can hamper identification of genuine climatic variations or lead to erroneous interpretations (Peterson et al., 1998).

Homogeneity tests can be broadly divided into 'absolute' and 'relative' methods. The former is applied to individual candidate stations to identify statistically significant breaks in data while relative methods entail comparison of correlated neighbouring stations with a candidate station to test for homogeneity. Reference series, which have ideally experienced all the broad climatic influences of the candidate but no artificial biases, are commonly used to detect inhomogeneity in relative methods (WMO, 2011), as well as to assess the quality of the homogenization process (Kuglitsch et al., 2009). Reference series themselves do not need to be homogeneous (Zhang et al., 2001; Caussinus and Mestre, 2004), but must encompass the same climatic signal as the candidate (Della-Marta and Wanner, 2006). Relative homogenization is more robust than absolute methods provided station records are sufficiently correlated (Wijngaard et al., 2003). However, relative approaches can be confounded by lack of long records at neighbouring stations for comparison, and by simultaneous changes in measuring techniques across a network (Peterson et al., 1998; Wijngaard et al., 2003).

All homogeneity approaches benefit from reliable metadata and station histories to account for breaks and potential outliers. Metadata can provide information such as location of station instruments, when and how observations were recorded, notes on instrument changes and malfunctions or any environmental changes (such as vegetation encroachment at the site). This information is critical in interpreting statistical homogeneity tests and for informing the nature and magnitude of adjustments that might be applied to data.

New techniques are emerging for the detection and adjustment of inhomogeneity in climate series (Cao and Yan, 2012; Toreti et al., 2012; Freitas et al., 2013; Mestre et al., 2013) and the correction of multiple change points using reference series (Peterson et al., 1998; Menne and Williams, 2005; Toreti et al., 2012). A comprehensive assessment of homogenization techniques for climate series was included in the scientific programme of the COST Action HOME ES 0601 Advances in Homogenisation Methods of Climate series: An integrated approach. The HOME objective was to develop a standardized method for homogenizing climate and environmental datasets. This led to the release of two new software packages: (i) HOMogenisation softwarE in R (HOMER) for the homogenization of monthly data; and (ii) $\mathrm{HOM} / \mathrm{SPLIDHOM}$ for daily data homogenization (HOME, 2013).

This paper aims to construct a temporally homogenized, long-term Island of Ireland Precipitation (IIP) archive by drawing on the tools of the HOME Cost Action and seminal works of Tabony (1980), Briffa (1984) and Burt et al. (2014). Our objectives are fourfold. First, we expand the existing catalogue of long-term monthly rainfall stations available in Ireland by recovering data for an additional eight stations. Where valuable but discontinuous records are available we reconstruct composite series. Second, we homogenize the expanded catalogue of 25 stations using the software and approach of the HOME COST action. Third, we use the expanded network to extend and update all stations to a common period of 1850-2010. Fourth, we assess variability and change within this expanded, extended and quality assured network. The remainder of the paper is organized as follows: Section 2 describes the datasets and methods used for data updating and preparation, steps involved in homogenizing the network and the techniques used to analyse variability and change. Result are presented and discussed in Section 3. Final conclusions and opportunities for further research as set out in Section 4.

\section{Data and methods}

Data analysis was executed in three stages: (i) preparation; (ii) homogenization; and (iii) analysis of variability and change across the homogeneous IIP network. Figure 1 illustrates the key steps involved in each stage with the following sections elaborating the datasets and methods used.

\subsection{Data preparation}

Existing long-term monthly precipitation records for 16 stations with different start and end dates for the Island of Ireland (IoI) were obtained from the Climatic Research Unit (http://www.cru.uea.ac.uk/cru/data/UK_ 


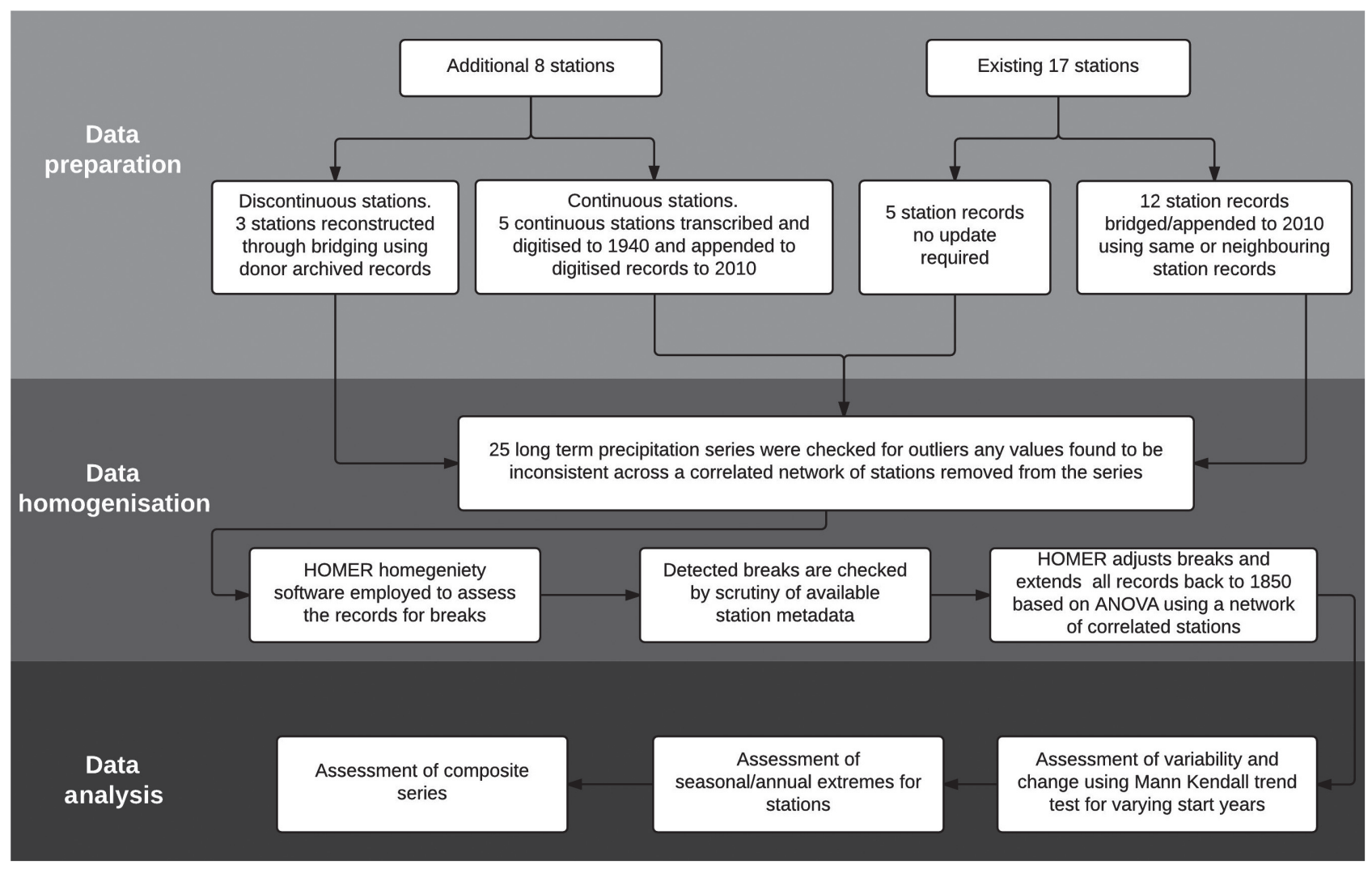

Figure 1. Workflow stages and key steps in data preparation, homogenization and analysis.

IR rainfall data/). All stations in this archive were updated to a common endpoint of 2010 using digitized precipitation records for the period 1941-2010. Precipitation records from 1850 to 2010 for Armagh were obtained from Prof. Butler at Armagh Observatory, Northern Ireland. For Ireland post-1940 data were obtained from Met Éireann while for Northern Ireland station data were acquired from the Centre for Environmental Data Archival (CEDA) at the British Atmospheric Data Centre (BADC). Five stations in the CRU archive required no updating and were employed as downloaded. For a further site (Phoenix Park), data for the same station was available. Following checks for consistency using an overlapping period, the series was updated. For the remaining 10 stations, records were discontinuous due to station closures or moves and updating was implemented by bridging to local stations. Following Barker et al. (2004) and Todd et al. (2014) seasonal regression analysis was used to bridge station records. In each case, seasonal mean precipitation series were derived for available data, then regression equations calculated for overlapping periods for final adjustment of donor records to match the primary station. Note the term 'donor stations' is used to refer to neighbouring stations with overlapping records.

An additional eight stations were recovered from the archives. Data was obtained from two sources at Met Éireann: (i) archived precipitation records collected prior to 1941 and held in paper form; and (ii) digitized records for selected stations (post-1940). Available hard-copy records were scrutinized for stations suitable for digitization based on criteria including: record length, fraction of missing data, availability of post-1941 digitized data, and geographical location. These procedures short-listed five records (Portlaw, Foulkesmills, Drumnsa, Galway and Mullingar) that comprise mainly continuous records from the 19th century to present. Following checks for consistency with overlapping periods, data for these stations were simply appended to the start of existing digitized station records for the period 1941-2010.

Three other discontinuous archived records (Rathdrum, Strokestown and Athboy) were also identified. Rather than losing the valuable information available for these sites, bridging and infilling from donor stations (using seasonal regression) was undertaken to develop continuous series. For these three stations suitable archived donor stations were also transcribed and digitized to extend primary station records back in time. For the period following primary station closure, composite monthly series from operational local stations were calculated for years up to 2010. Figure 2 provides details on the primary and donor archived stations selected for digitization and overlapping periods. Figure 3 maps the location of all 25 stations used in our analysis and shows record length for all stations following updating to 2010.

For each station, details on derived regressions and adjustment factors used for bridging stations are given in Appendix S1, Supporting Information. All regression models were significant at the 0.05 level. The poorest regressions were derived for Roches Point, Derry, Belfast and Ardara where a lack of suitable local donor stations 


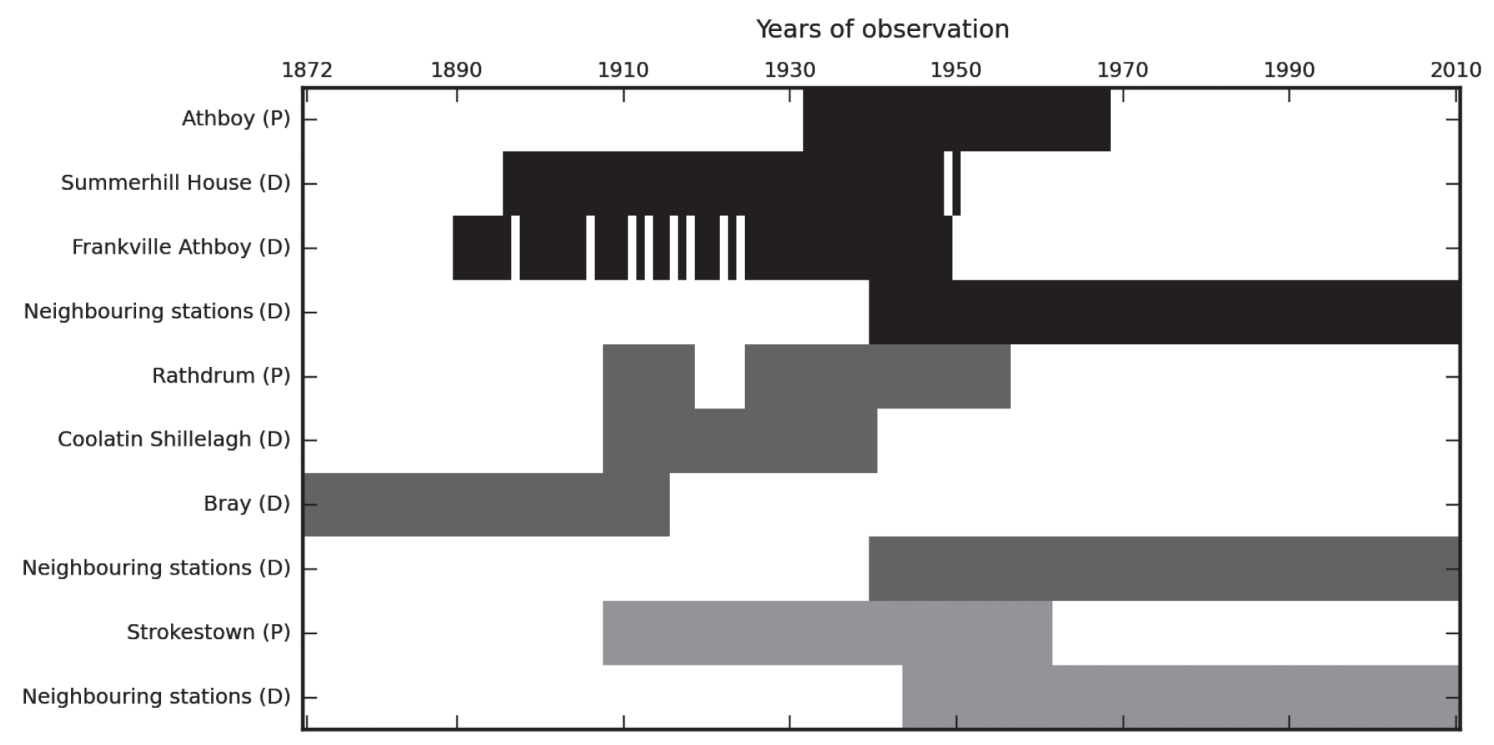

Figure 2. Primary stations (P) Athboy (black), Rathdrum (dark grey) and Strokestown (grey) and overlapping records for donor stations (D) used for bridging and infilling.

for bridging meant candidates were derived from further afield. However, with the exception of Enniscorthy, seasonally derived correction factors are $<10 \%$ but typically much lower (Table S1).

Metadata and methodological information were gathered for the CRU series (Jones, P.D. 2015; personal communication). When transcribing and digitizing the eight new stations careful note was made of available metadata and station notes on hardcopy records for both primary and donor stations. All metadata collected, together with the updating and bridging processes applied to the IIP network, are documented in Appendix S1, Section S2. This information was used to check breaks detected by the homogenization process described below.

\subsection{Data homogenization and extension to 1850}

The HOMER package was a key deliverable of the COST action HOME and represents a synthesis of homogenization approaches (Mestre et al., 2013), including PRODIGE (Caussinus and Mestre, 2004), ACMANT (Domonkos, 2011; Domonkos et al., 2011) and CLIMATOL (Guijarro, 2011). HOMER is an interactive semi-automatic method for homogenization where the user can take advantage of available metadata in the detection and correction of time series (Vertačnik et al., 2015). We deploy HOMER to detect and correct inhomogeneity in the 25 monthly IIP series and to extend all records to a common period 1850-2010.

HOMER detects change points (or breaks) using dynamic programming (Hawkins, 2001), penalized likelihood criteria pairwise comparisons, and joint segmentation (Picard et al., 2011). We deployed pairwise comparisons as adopted by PRODIGE. This algorithm implements optimal segmentation with dynamic programming, an information theory-based formula for determining the number of segments in time series (Caussinus and Lyazrhi, 1997), and a network-wide unified correction model based on a two factor analysis of variance (ANOVA) model (Caussinus and Mestre, 2004; Mestre et al., 2013; Mamara et al., 2014). In pairwise testing, reference series are treated as sections of the time series between two change points. Reference series are compared with all others from the same climate region to produce series of differences between the candidate and others in a defined network. Difference series are then tested for change points (Mamara et al., 2014). Once detected breaks have been checked against metadata, non-homogenous series are corrected using an ANOVA model (for a complete technical description, see Mestre et al., 2013; Mamara et al., 2014).

Creation of a reference network for a given candidate station is a key step in the homogenization process. The network can be defined based on geographic proximity or station correlation. To ensure that candidate stations have sufficient reference stations for each year of the series, it is necessary to set the minimum number of reference stations (Vertačnik et al., 2015). Rather than use geographic distance options for our relatively sparse network, first difference correlations were used to identify 12 reference stations for each candidate station as recommended in the literature (Alexandersson and Moberg, 1997; Peterson et al., 1998; Štěpánek and Mikulová, 2008; Coll et al., 2014). Further, the selection of 12 neighbours facilitated the homogenization and extension of all series to a common period of 1850-2010 while avoiding a known limitation of the software to correct when there are many blocks of missing contiguous data distributed across candidate and/or reference series (Coll et al., 2015).

We adopted a three-stage application of HOMER to allow greater scrutiny of detected inhomogeneity before corrections were applied. First, basic quality control and network analysis were performed. Outliers were identified using both HOMER and visual inspection by defining minimum and maximum monthly outliers as values 

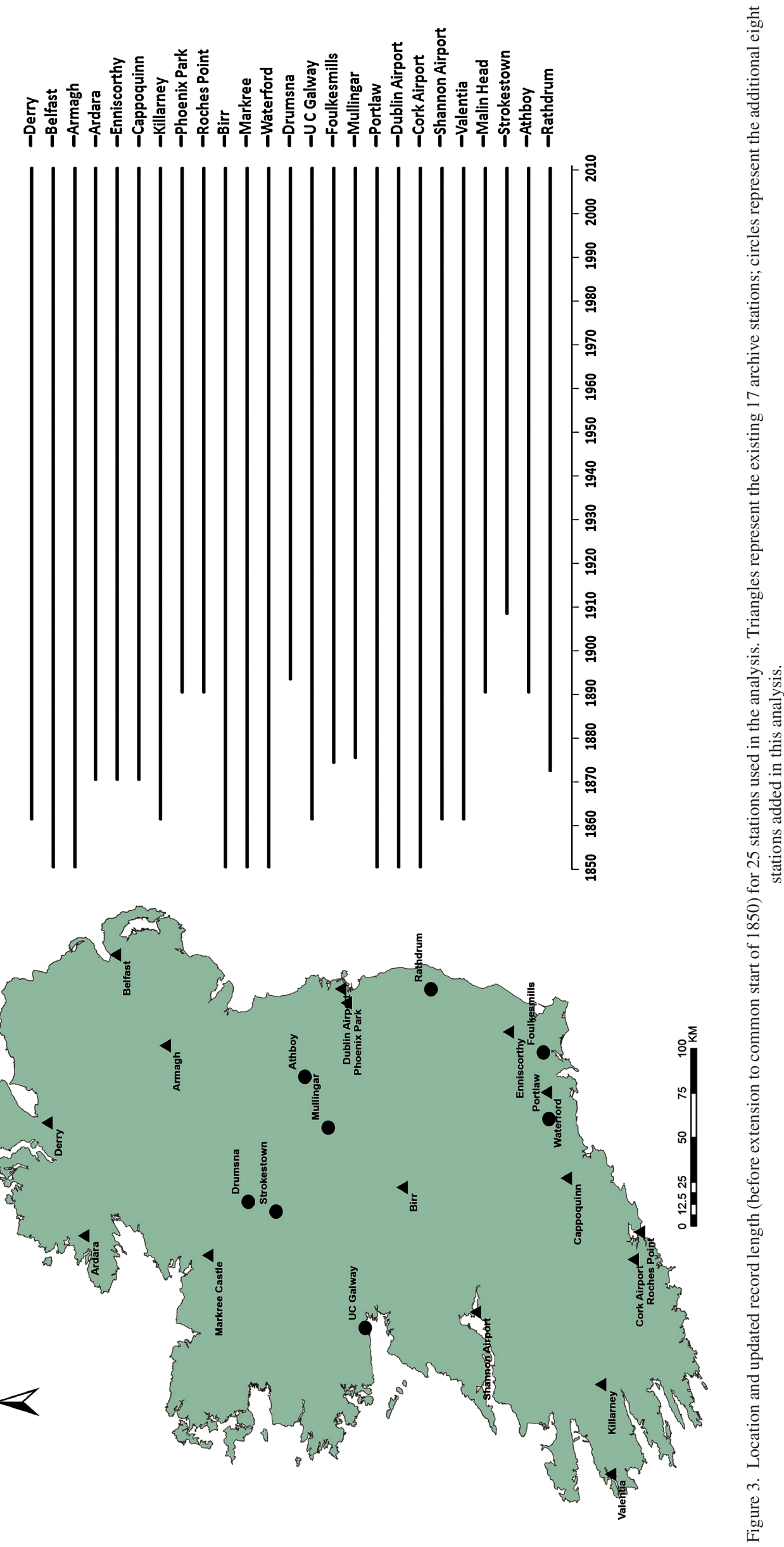
exceeding \pm 1.96 standard deviations from the respective series mean. Outliers were checked against correlated reference stations as well as metadata and any probable cases were removed. Second, HOMER was run to identify breaks within each time series. Detected breaks were not corrected automatically; all were checked for consistency with correlated reference stations and by scrutiny of metadata. Third, following confirmation of breaks with available metadata HOMER was used to correct series for inhomogeneity and missing values. Following the recommendations of Venema et al. (2012) we applied annual corrections in PRODIGE with multiplicative corrections applied using the amplitude of detected breaks. Hence, for an amplitude of +0.15 , data before the detected break were multiplied by 1.15 (increase in mean of $15 \%$ ). As a final step HOMER is used to infill missing data for all series to 1850. PRODIGE allows correction of the missing data using adjustment based on break amplitude with adjustment applied until the first detected change point of the series.

\subsection{Quality assuring homogenized series}

Following application of HOMER quality assurance of homogenized series was undertaken in three ways. First we examined sensitivity of break detection to network density. Previous experience recommends that at least $50 \%$ shared variance $\left(r^{2}\right)$ is needed between candidate and reference series (Scheifinger et al., 2003; Auer et al., 2005). At lower levels, detection of discontinuities can be hampered by statistical noise. Scarcity of long records means that station density is relatively low across the island, yet extension to a common period required selection of 12 reference stations for each candidate to avoid issues of excessive missing data. Both of these objectives have the potential to lessen the availability of sufficiently correlated reference stations. Thus, the sensitivity of break detection to network density was explored by re-running HOMER for all stations over the period 1941-2010 using a finer network of 211 digitized precipitation stations. Break detection frequency and consistency of timing of breaks in the period 1941-2010 using both networks was examined.

Second, the Pettitt (1979) statistic was used to examine the HOMER homogenized annual IIP station series for any remaining change points. Pettitt is an absolute, non-parametric test for detecting change points, and is relatively insensitive to outliers and skewed data (Pettitt, 1979). The null hypothesis (no change point in time series) against the alternative (an upward or downward change point in a given year) was tested at the 0.05 level. Finally, we constructed the IIP series from the unweighted average across all stations for the period 1850-2010, both to assess variability and change at the island level but also for comparison with overlapping periods in other long running series, including; England and Wales Precipitation (EWP) (Alexander and Jones, 2001) and storminess indices for the BI (Matthews et al., 2015). Spearman's rank correlations were also derived between seasonal and annual IIP series and the North Atlantic Oscillation Index (NAOI) (accessed http://www.cru.uea.ac.uk/cru/data/nao/).

\subsection{Analysing variability and change}

Variability and change was assessed for all 25 homogenized stations in the IIP network together with the IIP series. For each station 11-year moving averages for annual and seasonal [winter (DJF), and summer (JJA)] series were computed. Driest/wettest years were identified annually and seasonally for all 25 stations and the IIP series, with the latter compared with EWP. The non-parametric Mann-Kendall (MK) test (Kendall, 1975) was used to detect monotonic trends in every seasonal and annual mean series. The MK test statistic $(Z s)$ has mean of zero and variance of one. Positive (negative) $Z$ s indicates a positive (negative) trend in precipitation. The magnitude of $Z \mathrm{~s}$ indicates strength of the trend. Trend significance was assessed at the 0.05 level using a two-tailed test. The null hypothesis, $H_{0}$, of no trend (positive or negative) was rejected if $M K|Z s|>1.96$. Homogenized series were also checked for lag one serial correlation (but no autocorrelation was detected at the 0.05 level). Following Wilby (2006) and Murphy et al. (2013) dependency of trends on the period of record was investigated by varying the start year of the analysis. The MK Zs statistic was first calculated over the full record, i.e. 1850-2010, then 1851-2010 and so on, to a minimum record length of 30 years. Finally, trends in seasonal means for the IIP series were assessed using a moving windows approach for all possible start and end dates with a minimum record length of 10 years.

\section{Results and discussion}

\subsection{Homogenization and extension to 1850}

Following updating and bridging procedures (see Appendix S1), record lengths across the 25 IIP stations range between 101 and 161 years with mean 139.6 years. HOMER identified 12 reference stations within the network for each candidate station for pairwise comparison and joint detection of possible breaks. Table 1 provides the mean correlation coefficients $(r)$ along with the range of $r$ for each station and corresponding reference network. Mean $r$-values for all pairs of candidate and reference series ranged between 0.58 (Malin Head) and 0.80 (Foulkesmills). Outlier detection revealed 53 inconsistent monthly values across 16 stations. The station at the University College Galway (UCG) accounted for $30 \%$ of outliers and Valentia for $16 \%$, with the remainder spread across the other 14 stations. HOMER was first run on all series with known outliers included, and the results scrutinized; series were then re-processed in HOMER following the removal of outliers. However, the distribution of years with breaks detected by HOMER remained the same, indicating that for this network break detection by the programme is not sensitive to outliers.

Eleven stations were found to be homogenous, but 25 breaks were detected by HOMER across the other 14 stations. Multiple breaks were found in seven records: six in the UCG series; two for Malin Head, Belfast, Mullingar, Drumsna, Portlaw and Roches Point; and a single break point in each of the remaining seven series. Metadata 
Table 1. Mean and range of first difference correlation coefficients for the identified reference station networks for each of the 25 candidate stations.

\begin{tabular}{lcc}
\hline Station name & Mean $r$ & Range of $r$ \\
\hline Armagh & 0.76 & $0.70-0.82$ \\
Roches Point & 0.75 & $0.63-0.91$ \\
Athboy & 0.78 & $0.72-0.87$ \\
Foulkesmills & 0.80 & $0.69-0.92$ \\
Waterford & 0.78 & $0.66-0.92$ \\
Birr Castle & 0.76 & $0.70-0.87$ \\
Mullingar & 0.79 & $0.72-0.88$ \\
Drumsna & 0.75 & $0.66-0.89$ \\
Portlaw & 0.78 & $0.67-0.89$ \\
Phoenix Park & 0.73 & $0.64-0.98$ \\
Belfast & 0.72 & $0.66-0.82$ \\
Enniscorthy & 0.79 & $0.69-0.91$ \\
Derry & 0.70 & $0.58-0.80$ \\
Valentia & 0.71 & $0.64-0.83$ \\
Cappoquin & 0.79 & $0.73-0.88$ \\
Killarney & 0.71 & $0.67-0.83$ \\
Cork Airport & 0.75 & $0.62-0.91$ \\
UC Galway & 0.67 & $0.57-0.78$ \\
Strokestown & 0.79 & $0.73-0.89$ \\
Shannon Airport & 0.71 & $0.62-0.81$ \\
Rathdrum & 0.78 & $0.70-0.86$ \\
Dublin Airport & 0.74 & $0.64-0.98$ \\
Malin Head & 0.58 & $0.43-0.75$ \\
Markree Castle & 0.75 & $0.62-0.83$ \\
Ardara & 0.69 & $0.58-0.80$ \\
\hline
\end{tabular}

scrutiny revealed that 20 of the detected breaks coincided with issues such as changes in gauge size and position, stations closures and moves, previous bridging/infilling and updating of records. Table 2 lists years of break detection alongside metadata for each case. Years for which no explanation could be found are highlighted in bold. There is little consistency in timing of break detection throughout the network with 12 breaks occurring before 1941 (i.e. prior to digitization) and 13 after. Overall break detection frequencies are consistent with other studies in Europe (e.g. Domonkos, 2014 and references therein). Low break detection frequencies, particularly in early parts of the record, are testimony to the quality of work by Tabony (1980) and Briffa (1984) in constructing composite series.

The amplitude of detected breaks is presented in Table 2. Amplitude provides an indication of the magnitude of breaks detected and the adjustment needed to correct the inhomogeneity. Across all stations and detected breaks the mean absolute amplitude was 0.15. The largest break (amplitude 0.40) was found for Drumsna in 1941 and attributed to a leaky gauge and position changes (Table 2). The smallest break (amplitude 0.07) was found in 1930 at Roches Point and associated with a change from an 8 to 5 inch gauge.

Five breaks could not be explained by metadata. Rather than blindly apply adjustments, these cases were further investigated by employing the Mann Kendall (MK) test to examine the persistence of trends for uncorrected series relative to trend persistence for the fully homogenized network (Figure 4). Attention was paid to: (i) persistence of trends relative to the pattern of change across the network as a whole; and (ii) notable changes in trend persistence for individual stations before and after detected change points. Large deviations from trends in the homogenized records emerged. For Mullingar tests commencing before the identified break point in 1937 show persistently significant negative trends; after the break point positive trends are found. Other large deviations in trend persistence around identified break points are found for Belfast, Enniscorthy and Roches Point. Given the proximity of the break at UCG to the end of record this was more difficult to assess; however, confidence in this break is increased given the very high MK $Z \mathrm{~s}$ scores for tests commencing after 1950 together with the number of previously verified breaks (5) for this record. Given the suspicion raised, all breaks (confirmed and unconfirmed by metadata) were subject to adjustment. Simultaneous with correction all stations were extended to a common start year of 1850 .

Detected breaks were corrected annually with multiplicative adjustments relative to the break amplitude applied equally across monthly series. This decision was made as the HOME COST action found the application of yearly corrections by PRODIGE to be more stable and accurate, and hence these are currently recommended for homogenization of precipitation networks (Venema et al., 2012). In a maritime climate such as Ireland variability of precipitation from month to month is low enough to allow such correction. In addition, Auer et al. (2005) and Moisselin and Canellas (2005) recommend that the same annual adjustment factor be applied to all months.

\subsection{Quality assurance of homogenized series}

Table 1 reports correlation coefficients for identified reference stations for each candidate. However, mean reference network correlations for Derry, UCG, Ardara and particularly Malin Head (mean $r=0.58$ ) fall below the recommended correlation threshold of 0.71 (i.e. $r^{2}=0.50$ ) (Scheifinger et al., 2003; Auer et al., 2005). We therefore assessed sensitivity of break detection to network density by re-running HOMER for candidate stations using a finer density network for the period 1941-2010. In the main, consistency of break detection frequency and timing add confidence to results. However, two minor differences resulted. First, a change in year of break is found at Malin Head from 1966 to 1955 (1941-2010). The latter is more in line with metadata. Second, at Drumsna two new breaks are detected in 1965 and 1968 in the 1941-2010 run. Metadata suggest a defective gauge in 1968. In 1967 the gauge is reported as being in good order while in 1969 the gauge is replaced (see Appendix S1).

Following homogenization the Pettitt (1979) test was applied to annual series for each IIP station to check for residual breaks. From Figure 5 a consistent upward change point in the early 1920s is apparent for many stations and significant $(p$-values $<0.05)$ at Strokestown, Markree Castle, Athboy, Malin Head and Mullingar. The consistency of timing and direction of these, in the absence 
Table 2. Detected break points across 14 stations showing year and amplitude of break point, number of years in the series tested and associated metadata. Breaks shown in bold have no explanation in metadata.

\begin{tabular}{lc}
\hline Station & $\begin{array}{c}\text { Year of break } \\
\text { (amplitude) }\end{array}$ \\
\hline $\begin{array}{l}\text { Cork Airport } \\
(1850-2010)\end{array}$ & $1958(+0.13)$ \\
$\begin{array}{l}\text { Birr } \\
(1850-2010)\end{array}$ & $1851(+0.27)$ \\
& \\
$\begin{array}{l}\text { Malin Head } \\
(1891-2010)\end{array}$ & $1924(+0.13)$ \\
\end{tabular}

Years Details from metadata

161

Station record originally constructed by Tabony (1980) using a composite of stations. Prior to 1962 data is reported from University College Cork which is at a lower elevation and is likely to explain the detected break

161 Station record originally constructed by Tabony (1980) using Birr and composite of stations up to 1971. Updated to 1994 by Jones and Conway (1997) and updated to 2010 using Birr station records from Met Éireann. Change from 15" to $5^{\prime \prime}$ gauge during 1850 s may have caused detected break

Station record originally constructed by Tabony (1980) using composite of stations up to 1975 . Readings were made at the telegraphic reporting station (Lloyds tower at a height of $230 \mathrm{ft}$ ). In 1921 station moved to the coast guard station and at a height of approximately $20 \mathrm{ft}$ above msl. From 1921 to 1940 readings were taken at $01.00,07.00,10.00,15.00,18.00$ and 21.00 GMT but rarely all six times. From 1940 to 1950 only sporadic readings were taken at 04.00 and 13.00 GMT. The year 1950 reading times changed again to 0.600 , 12.00 and 18.00 GMT. In May 1955 a new synoptic station opened, with subsequent readings taken on the hour

$\begin{array}{ll}\begin{array}{l}\text { Killarney } \\ (1862-2010)\end{array} & 1980(+0.13) \\ \begin{array}{l}\text { Enniscorthy } \\ (1871-2010)\end{array} & \mathbf{1 8 8 8}(\mathbf{- 0 . 1 0}) \\ \begin{array}{l}\text { Belfast } \\ (1850-2010)\end{array} & 1898(+0.09) \\ & \mathbf{1 9 4 5}(-\mathbf{0 . 0 9}) \\ \begin{array}{l}\text { Mullingar } \\ (1876-2010)\end{array} & 1950(-0.24) \\ \begin{array}{l}\text { Rathdrum } \\ (1873-2010)\end{array} & 1918(+0.10) \\ \begin{array}{l}\text { Drumnsa } \\ (1893-2010)\end{array} & 1917(-0.22) \\ \end{array}$

149 Station record originally constructed by Briffa (1984) from composite of stations up to 1980. Updated to 1994 by Jones and Conway (1997). Valentia used in 1972-1976 to infill records and may have caused detected break

140 Station record originally constructed by Briffa (1984) from composite of stations up to 1980. Updated to 1994 by Jones and Conway (1997). Break unexplained

161 Station record originally constructed by Tabony (1980) using composite of stations up to 1977. In 1902 the gauge moved to Royal Academic Institute where estimates were applied and may have been the cause of the detected break in 1898. No issues in metadata to explain break detected in 1945

135 No explanation in the metadata for break in 1937. Archived station Belvedere House, Mullingar closed in 1950 and was updated to 2010 using station records at Mullingar Town and may have caused break detected in 1950

138 Archived station at Rathdrum was infilled from donor station at Coolatin for the period 1918-1923 and may have been the cause of detected break

118 Missing months infilled from Strokestown 1921 and 1949. These years and 1938 considered too low. 1939 records of Drumsna never appeared in British rainfall. $19425^{\prime \prime}$ gauge 1' above ground leaking. Very exposed open flat country. Partly shaded by fencing. New gauge installed in sheltered position nearby for comparison. 1943 new gauge now official instrument

$\begin{array}{ll}\begin{array}{l}\text { Shannon } \\ \text { Airport } \\ (1861-2010)\end{array} & 1930(-0.07) \\ \begin{array}{l}\text { Roches Point } \\ (1890-2010)\end{array} & \mathbf{1 9 5 6}(\mathbf{- 0 . 1}) \\ & 1990(+0.16) \\ \text { UCG } & 1874(-0.21) \\ (1862-2010) & 1907(-021) \\ & 1920(+0.22) \\ & 1933(-0.13) \\ & 1952(+0.18) \\ \text { Portlaw } & \mathbf{1 9 8 7}(+\mathbf{0 . 1 0}) \\ (1850-2010) & 1941(-0.10) \\ & 1965(+0.12)\end{array}$

150 Station record originally constructed by Tabony (1980) using composite of stations up to 1977 . Change from an $8^{\prime \prime}$ to $5^{\prime \prime}$ gauge in 1930

121 Station record originally constructed by Tabony (1980) using composite of stations to the 1970s. Updated to 1990 by Jones and Conway (1997). Bridged to 2010 using Cork Airport which may have caused the detected break in 1990. Limited metadata with no issues that may have caused detected 1956 break 149 Metadata show low values recorded in 1875, 1907, 1920, 1921 and 1933 which may be due to observer data entry errors. Up to 1951 the values had been recorded in inches but changed in 1952 to millimetres and could have been converted incorrectly which may explain the detected break in 1952. New station opened 1965 but no issues are identified to explain the break in 1987

161 Metadata show that from 1940s to the late 1960s several issues occurred. The rain gauge had to be replaced several times due to damage and faults. The observer was also using a mm rain-measure and dividing by 2 to convert to inches. In addition, over this period vegetation was high and too close to gauge which may have caused undercatch

Ardara $1983(+0.07)$

141 Station originally constructed by Briffa (1984) from composite of stations up to 1980. Updated to 1994 by Jones and Conway (1997) may have caused detected break in 1983 


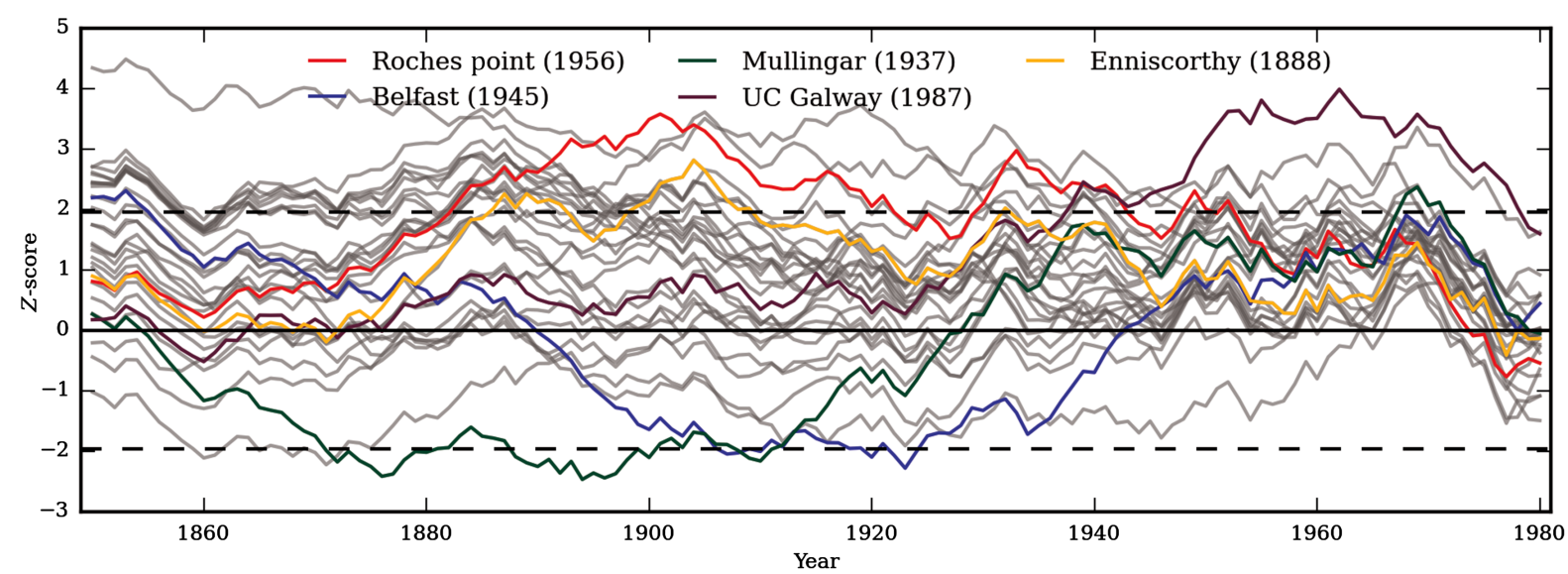

Figure 4. Persistence of trends for stations with breaks unconfirmed by metadata relative to the persistence of trend for completely homogenized records for all 25 stations (grey lines and including 11 stations with no breaks detected). Dotted horizontal lines represent critical values beyond which trends are significant at 0.05 level.

of evidence for changes in measurement techniques across the island at this time, increases confidence that such changes are climatically driven. There is no evidence from metadata to raise suspicion of a simultaneous change in measurement practice at this time.

However, we flag caution for Malin Head where a break (associated with station move) is also detected (and corrected) by HOMER in 1924. Given the low mean $r$ of this candidate with reference stations the amplitude of detected break may be prone to error. Significant upward change points are also detected at UCG (1915), Ardara (1933) and Drumsna (1933) with the annual series for each presented in Figure 5. At UCG limited metadata are available but we note that the detected break is small in relative terms with a $3.5 \%$ increase in mean annual precipitation for the post-1915 record. We also note no change in trend persistence at UCG around 1915 (Figure 4).

The Pettitt test revealed a more complex situation at Ardara and Drumsna where a simultaneous break point is detected in 1933. Drumsna is part of Ardara's reference network for pairwise detection and vice versa. Metadata reveal separate issues at both stations in this year which is problematic for relative detection methods with the consequence that HOMER may have missed an artificial break in both series. The Drumsna gauge is known to underestimate rainfall prior to 1940. HOMER detected and corrected a break in 1944. At Ardara, Briffa (1984) applied a large bridging correction factor $(+1.57)$ between 1932 and 1934. However, 1933 is also the second driest in the IIP (see below) and Drumsna series and driest at Ardara. Absolute changes in mean annual precipitation for records after 1933 are also very similar with a $5.8 \%$ and $5.3 \%$ increase evident for Drumsna and Ardara, respectively. Given this complexity caution is also flagged for both these series. For all three series (UCG, Ardara and Drumsna) the absolute magnitude of breaks are small and there is no evidence of major changes in trend persistence around these years. We find little evidence from metadata that breaks were missed by HOMER. For Markree Castle, Waterford and Phoenix Park there is reference to gauge position and height changes early in the record that are not detected by either HOMER or the Pettitt test.

\subsection{Variability and change in the IIP network}

Variability and change was assessed across the catalogue of 25 HOMER homogenized rainfall series. Figures 6-8 present annual, winter (DJF) and summer (JJA) smoothed series for each station along with trend persistence for both homogenized (1850-2010) and non-homogenized series (start year to 2010). We use an 11-year moving average to highlight low-frequency variability. For stations revealing breaks, MK Zs statistics before/after homogenization show large differences in trends. At Mullingar the trend in annual precipitation changes from significant ( 0.05 level) negative to significant positive. At Killarney, Cork, UCG and Malin Head, exceptionally large MK Zs scores in annual precipitation are removed following homogenization. Such differences highlight the importance of this work in increasing the confidence with which variability and change within the network can be assessed following homogenization.

Annual indices for the majority of stations show non-significant positive trends throughout the record. However, Killarney, Cappoquinn and Foulkesmills show negative trends for long records. The greatest number of significant $(0.05$ level) trends was found for tests commencing in the 1880 s, with trend significance highly dependent on period of record tested. In winter, with the exception of Foulkesmills, Cork Airport and Cappoquinn, long records show a tendency for positive trends. The most significant $(p<0.05)$ positive trends are found for records commencing before 1890 at Markree Castle, Malin Head and Ardara. However, in winter shorter records are not representative of longer-term behaviour with all stations showing negative trends for records commencing after 1980. In summer, long records show a tendency for negative trends, with significant (0.05 level) trends found for stations in the south and east (Killarney, Cappoquinn, Enniscorthy, Foulkesmills, Athboy and Rathdrum) for 


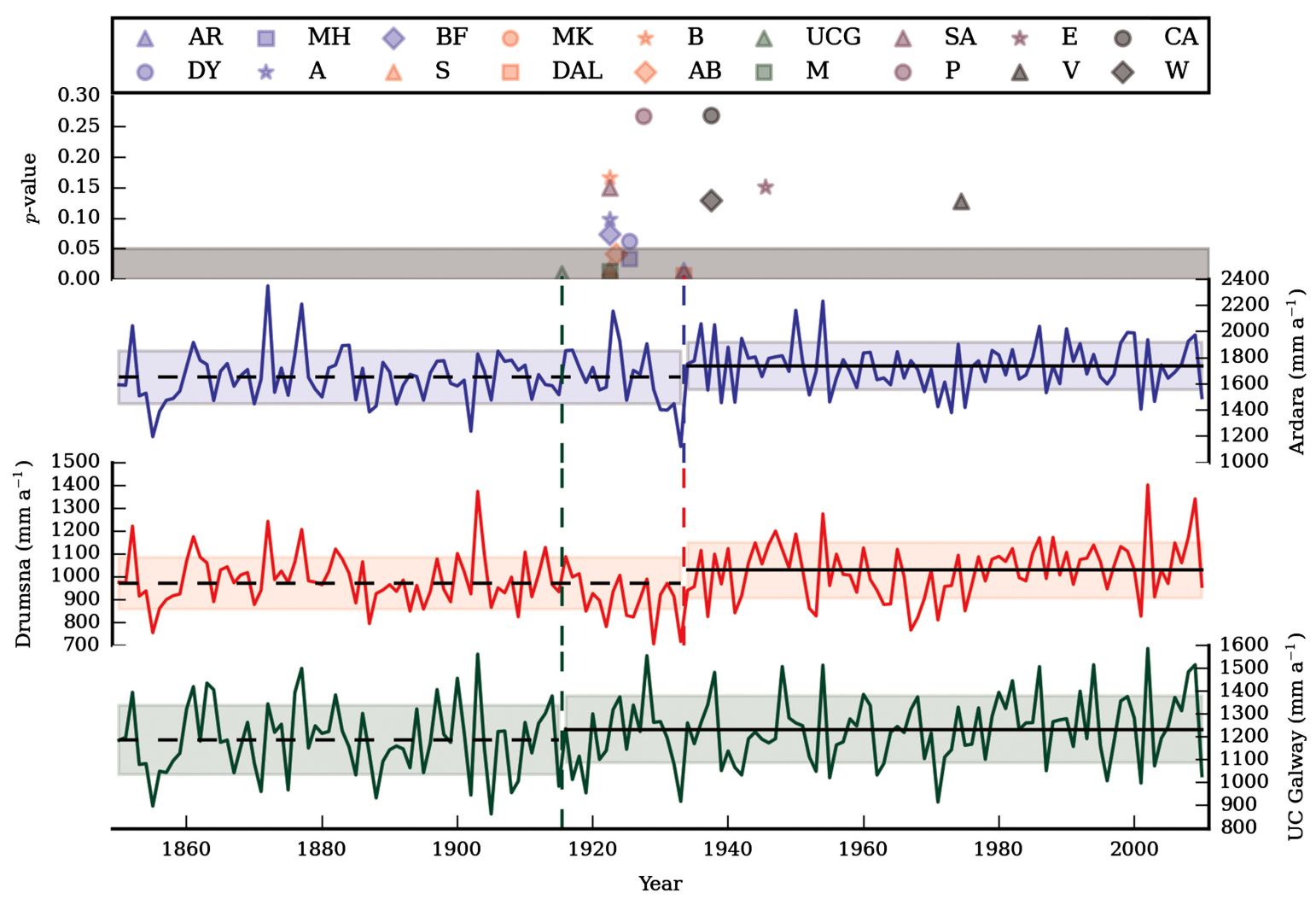

Figure 5. (a) Pettitt test for change points in mean annual precipitation. The grey shaded region indicates the region in which $p$-values are interpreted as significant (0.05 level). Time series plots (lower 3 axes) illustrate the mean annual precipitation at the stations with significant change points outside the 1920s (see text for further detail). These change points are highlighted with dotted vertical lines which correspond to the respective time series. Note that Ardara and Drumsna both have change points in 1933. The dotted (solid) black horizontal lines illustrates mean values before (after) the identified change point; the shaded region spans \pm 1 standard deviation.

tests commencing before 1880. Again, shorter records are not representative of long term trends. For tests run from the mid-1950s onwards all stations show positive trends, many of which are significant from the mid-1960s to mid-1970s.

We also assessed notable years both seasonally and annually for the extended and homogenized network. Table 3 shows the wettest/driest years for each station. On an annual basis the exceptionally wet years 2002 and 1872 stand out. Year 1872 was the wettest at Ardara, Derry, Cappoquinn and Waterford with 2002 being wettest at Belfast, Strokestown, Drumsna, UCG and Dublin Airport. The year 1887 is the most frequently identified driest year (six stations), followed by 1933 (four stations) and 1893 (three stations). Years 1891 and 1964 rank as those with the driest winters in nine and six stations, respectively. Years 1877, 1994 and 1995 stand out as wettest ranked winters across 12 stations. In summer, 1995 is driest at six stations (Armagh, Athboy, Phoenix Park, Foulkesmills, Enniscorthy and Rathdrum) while 1976 is driest at Belfast, Birr and Mullingar. In terms of wettest summers, 1861 ranks top across eight stations located along the west coast while 1958 is wettest for stations in the east. Latter years of the 2000s also stand out because of wet summers (in 2007, 2008 and 2009). Spring 1947 was the wettest for 15 stations with both 1995 and 1976 notable as the driest springs.

\subsection{Variability and change in the IIP series}

Figure 9 shows an annual and seasonal comparison between the smoothed (11-year moving average) IIP and EWP series for the period 1850-2010. Of note is the close correspondence of series across all seasons. Table 4 shows the ranks of seasonal and annual wettest and driest years for the IIP series. The wettest year in the 161-year record is 1872 with wettest seasons being 1994 (winter), 1947 (spring), 1861 (summer) and 2000 (autumn). In the EWP series for the period analysed 1872 is also the wettest year while winter 1994 ranks fourth wettest; 1947 ranks second in spring. The wettest summer in the EWP series for 1850-2010 is 1912 which ranks fourth in IIP. In both series 2000 is the wettest autumn in the period. The 1870 s feature frequently in the wettest ranks for the homogenized IIP series. In addition to 1872 being the wettest year, 1877 ranks as the seventh wettest year and the fifth wettest winter, 1879 is the third wettest summer and 1875 the fourth wettest autumn. The 2000s also feature strongly in the ranks for wettest summers and autumns. The sequence of very wet summers in Ireland in 2007, 2008 and 2009 rank as eighth, second and fourth wettest summers, respectively over 1850-2010. For IIP the driest year is 1887 which ranks second in EWP, while the driest summer is 1995 in both series for the period 1850-2010. Spring 1893 is the driest in both series. For 


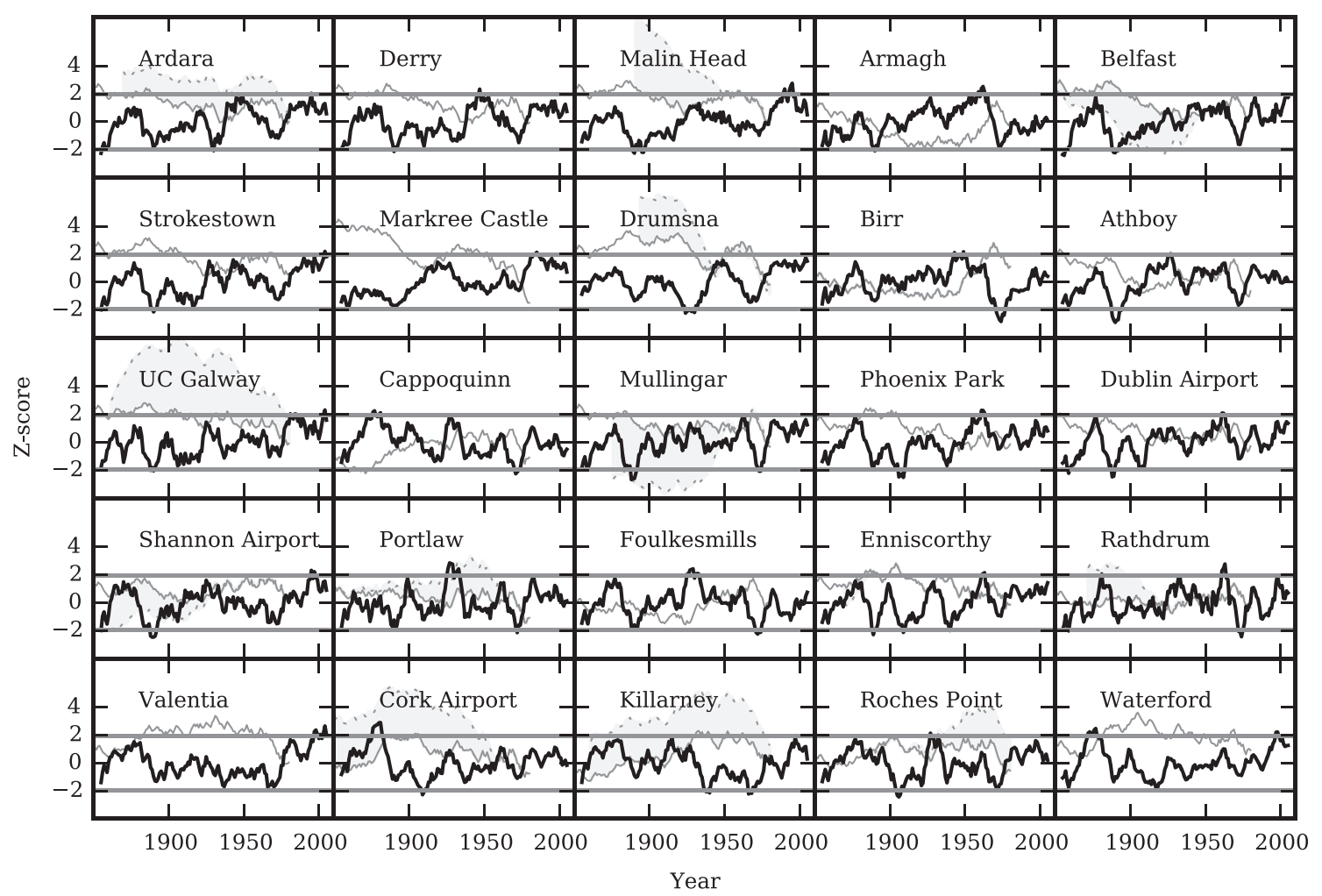

Figure 6. Homogenized annual time series for all stations smoothed with an 11-year moving average (black line). MK $Z$ scores are shown before and after homogenization where applicable (dotted: unhomogenized; solid: homogenized/no breaks detected) calculated for varying start years (which are given by the $x$-coordinate). The heavy grey lines indicate \pm 1.96 ; absolute values exceeding these bounds are interpreted as significant at the 0.05 level.

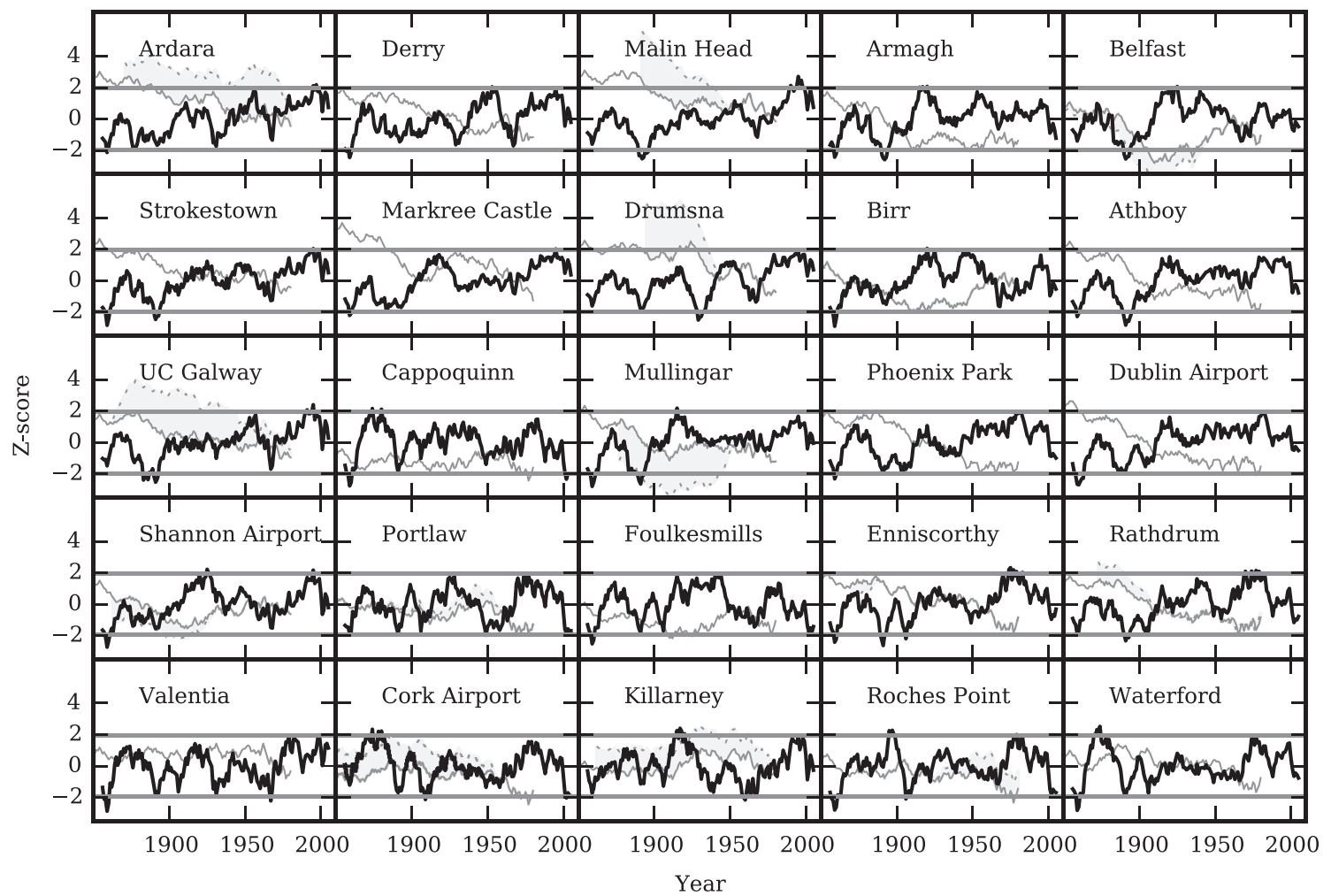

Figure 7. Homogenized winter time series for all stations smoothed with an 11-year moving average (black line). MK $Z$ scores are shown before and after homogenization where applicable (dotted: unhomogenized; solid: homogenized/no breaks detected) calculated for varying start years (which are given by the $x$-coordinate). The heavy grey lines indicate \pm 1.96 ; absolute values exceeding these bounds are interpreted as significant at the 0.05 level. 


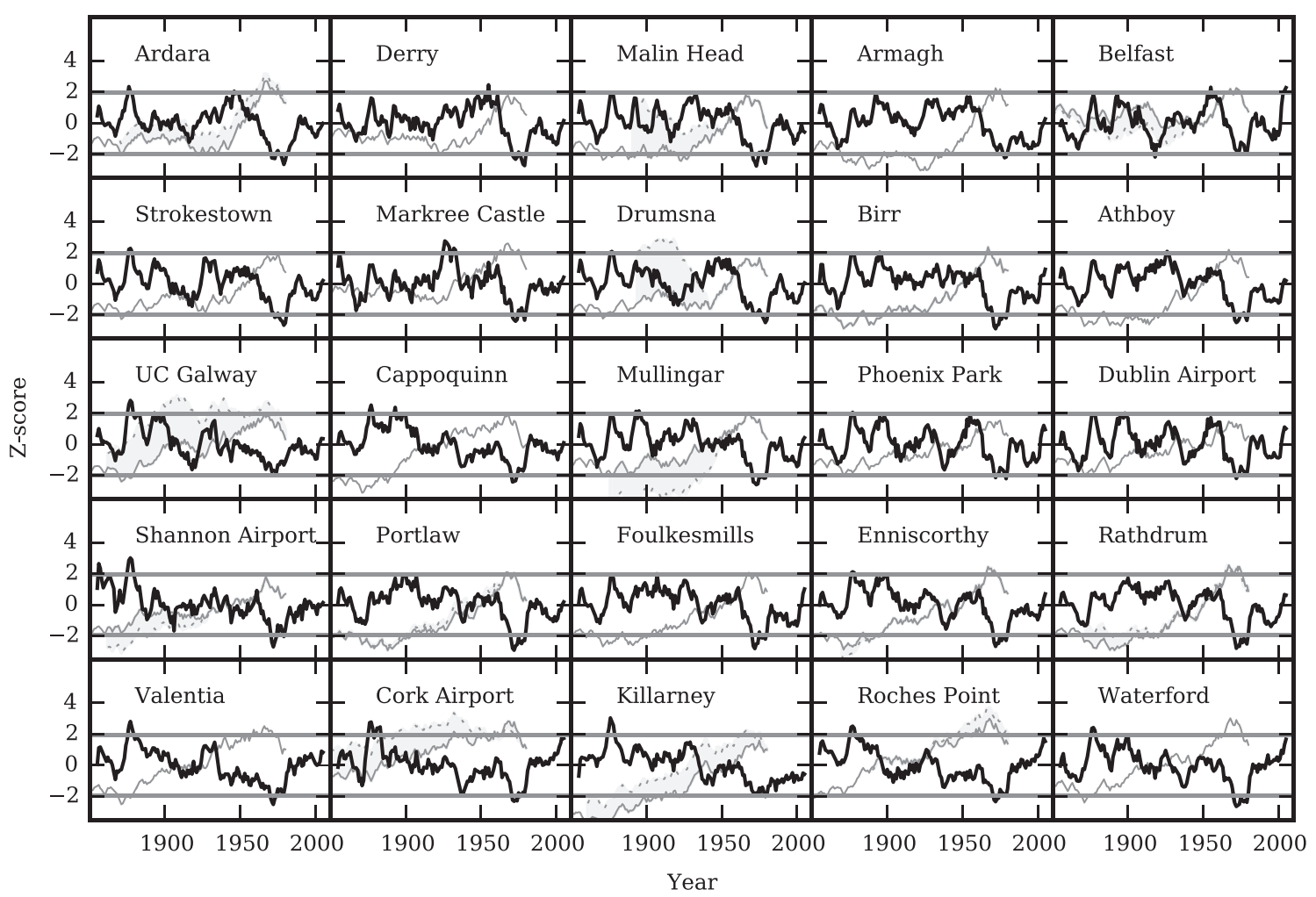

Figure 8. Homogenized summer time series for all stations smoothed with an 11-year moving average (black line). MK $Z$ scores are shown before and after homogenization where applicable (dotted line: unhomogenized; solid line: homogenized/no breaks detected) calculated for varying start years (which are given by the $x$-coordinate). The heavy grey lines indicate \pm 1.96 ; absolute values exceeding these bounds are interpreted as significant at the 0.05 level.

Table 3. Seasonal and annual wettest and driest years for each station in the extended and homogenized IIP network 1850-2010.

\begin{tabular}{|c|c|c|c|c|c|c|c|c|c|c|}
\hline \multirow[t]{2}{*}{ Station } & \multicolumn{2}{|c|}{ Winter } & \multicolumn{2}{|c|}{ Spring } & \multicolumn{2}{|c|}{ Summer } & \multicolumn{2}{|c|}{ Autumn } & \multicolumn{2}{|c|}{ Annual } \\
\hline & Wettest & Driest & Wettest & Driest & Wettest & Driest & Wettest & Driest & Wettest & Driest \\
\hline Ardara & 1937 & 1963 & 1986 & 1929 & 1861 & 1984 & 1954 & 1933 & 1872 & 1933 \\
\hline Derry & 1994 & 1891 & 1907 & 1929 & 1956 & 1885 & 1872 & 1915 & 1872 & 1933 \\
\hline Malin Head & 1995 & 1891 & 1916 & 1900 & 1861 & 1900 & 1967 & 1894 & 1954 & 1900 \\
\hline Armagh & 1877 & 1891 & 1947 & 1870 & 2007 & 1995 & 1870 & 2007 & 1852 & 1933 \\
\hline Belfast & 1877 & 1964 & 1947 & 1875 & 2007 & 1976 & 1954 & 1933 & 2002 & 1855 \\
\hline Strokestown & 1994 & 1891 & 1947 & 1929 & 1861 & 1913 & 1954 & 1933 & 2002 & 1921 \\
\hline Markree & 1995 & 1964 & 1985 & 1852 & 1861 & 1864 & 1917 & 1856 & 1924 & 1864 \\
\hline Drumsna & 1994 & 1964 & 1947 & 1929 & 1861 & 1909 & 1954 & 1922 & 2002 & 1929 \\
\hline Birr & 1995 & 1964 & 1947 & 1915 & 2007 & 1976 & 2000 & 1912 & 1946 & 2003 \\
\hline Athboy & 1994 & 1891 & 1947 & 1893 & 1958 & 1995 & 1944 & 1893 & 1924 & 1893 \\
\hline UC Galway & 1995 & 1891 & 1986 & 1918 & 1879 & 1940 & 1954 & 1871 & 2002 & 1905 \\
\hline Cappoquinn & 1883 & 1992 & 1931 & 1893 & 1903 & 1909 & 1875 & 1919 & 1872 & 1921 \\
\hline Mullingar & 1915 & 1891 & 1947 & 1953 & 1861 & 1976 & 2000 & 1922 & 2002 & 1887 \\
\hline Phoenix Park & 1979 & 1891 & 1947 & 1929 & 1958 & 1995 & 1960 & 1904 & 1958 & 1887 \\
\hline Dublin Airport & 1979 & 1964 & 1947 & 1929 & 1958 & 1887 & 2002 & 1904 & 2002 & 1887 \\
\hline Shannon Airport & 1995 & 1964 & 1994 & 1893 & 1861 & 2006 & 2000 & 1933 & 2008 & 1933 \\
\hline Portlaw & 1966 & 1855 & 1931 & 1896 & 1903 & 1869 & 2006 & 1919 & 1903 & 1887 \\
\hline Foulkesmills & 1912 & 1907 & 1947 & 1990 & 1912 & 1995 & 1875 & 1978 & 1928 & 1887 \\
\hline Enniscorthy & 1966 & 1855 & 1947 & 1893 & 1997 & 1995 & 1875 & 1969 & 1960 & 1893 \\
\hline Rathdrum & 1966 & 1891 & 1947 & 1893 & 1958 & 1995 & 1960 & 1893 & 1966 & 1893 \\
\hline Valentia & 1915 & 1934 & 1913 & 1893 & 2009 & 1940 & 2000 & 1932 & 2009 & 1971 \\
\hline Cork Airport & 1883 & 1855 & 1947 & 1990 & 1878 & 1869 & 1881 & 1942 & 1881 & 1854 \\
\hline Killarney & 1995 & 1963 & 1903 & 1893 & 1861 & 2006 & 1916 & 1922 & 1861 & 1971 \\
\hline Roches Point & 1900 & 1992 & 1947 & 1990 & 2008 & 1909 & 1960 & 1919 & 1928 & 1887 \\
\hline Waterford & 1912 & 1855 & 1947 & 1893 & 1997 & 1913 & 2006 & 1919 & 1872 & 1893 \\
\hline
\end{tabular}




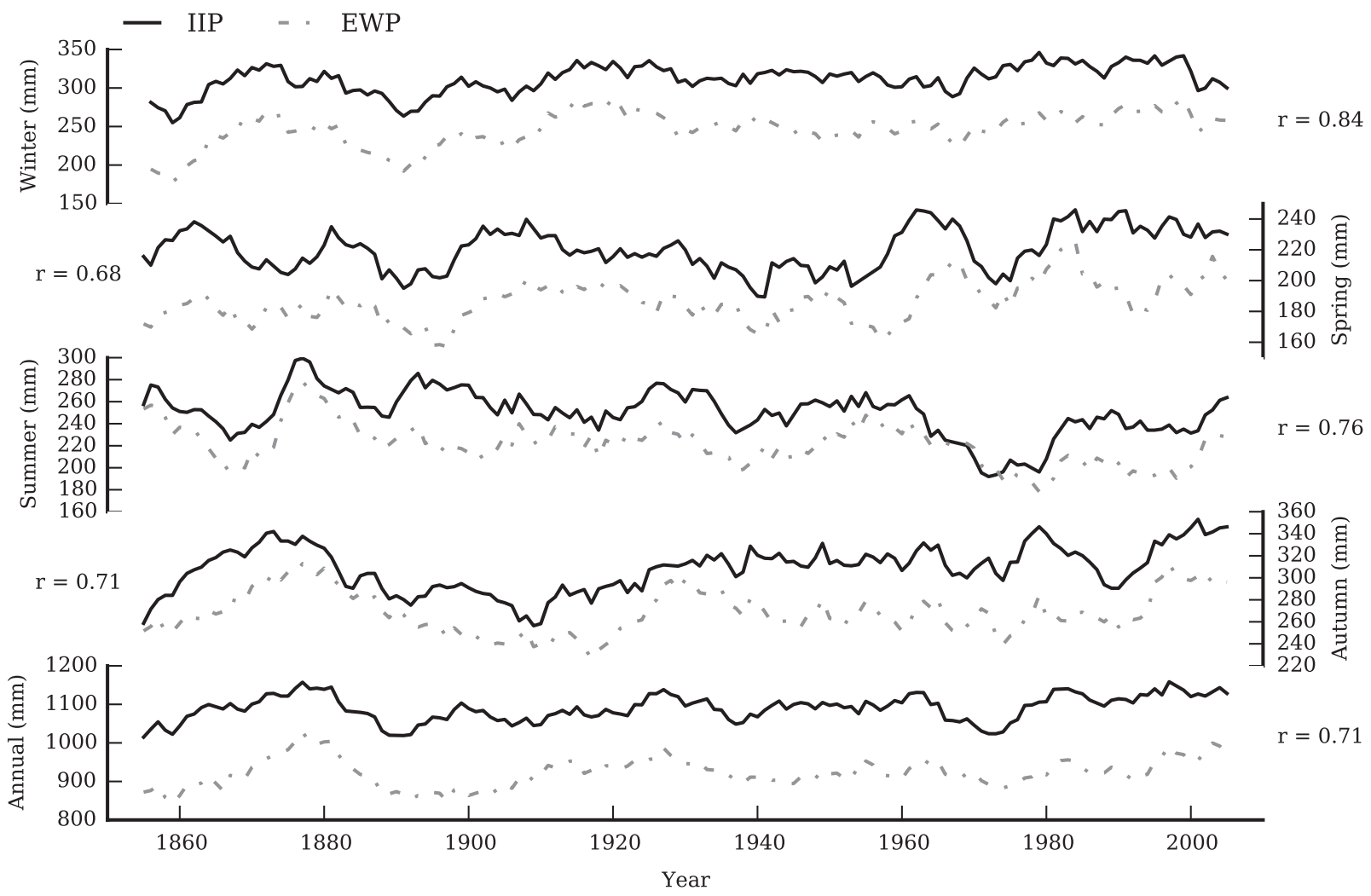

Figure 9. Comparison of smoothed (11 year moving average) IIP) and EWP (mm) for the common period 1850-2010. Plotted from top are winter, spring, summer, autumn and annual series. Also shown are Spearman's rank correlation coefficients.

Table 4. Top 10 ranked wettest and driest seasons and years from the homogenized and extended Island of Ireland precipitation (IIP) series $1850-2010$.

\begin{tabular}{|c|c|c|c|c|c|c|c|c|c|c|}
\hline \multirow[t]{2}{*}{ Rank } & \multicolumn{2}{|c|}{ Winter } & \multicolumn{2}{|c|}{ Spring } & \multicolumn{2}{|c|}{ Summer } & \multicolumn{2}{|c|}{ Autumn } & \multicolumn{2}{|c|}{ Annual } \\
\hline & Wettest & Driest & Wettest & Driest & Wettest & Driest & Wettest & Driest & Wettest & Driest \\
\hline First & 1994 & 1891 & 1947 & 1893 & 1861 & 1995 & 2000 & 1933 & 1872 & 1887 \\
\hline Second & 1995 & 1964 & 1981 & 1990 & 2008 & 1913 & 2006 & 1922 & 2002 & 1933 \\
\hline Third & 1883 & 1855 & 1913 & 1929 & 1879 & 1869 & 1954 & 2007 & 2009 & 1855 \\
\hline Fourth & 1915 & 1934 & 1986 & 1944 & 2009 & 1870 & 1875 & 1919 & 1852 & 1971 \\
\hline Fifth & 1877 & 1953 & 1920 & 1887 & 1912 & 1976 & 1982 & 1912 & 1928 & 1893 \\
\hline Sixth & 1966 & 2006 & 1897 & 1915 & 1958 & 1975 & 1944 & 1879 & 1903 & 1975 \\
\hline Seventh & 1990 & 1858 & 1993 & 1975 & 1860 & 1983 & 1960 & 1854 & 1877 & 1953 \\
\hline Eighth & 1869 & 1874 & 2002 & 1984 & 2007 & 1940 & 2002 & 1855 & 1960 & 1921 \\
\hline Ninth & 1937 & 1963 & 1862 & 1875 & 1985 & 2006 & 1916 & 1893 & 1924 & 1854 \\
\hline Tenth & 1974 & 1888 & 2006 & 1938 & 1852 & 1959 & 2009 & 1942 & 1958 & 1919 \\
\hline
\end{tabular}

the IIP record 1933 is the driest autumn while the driest winter was recorded for 1891 followed by 1964.

Strong correspondence is also evident with the storminess indices produced by Matthews et al. (2015) for the BI. Year 1872 (wettest year in IIP series) ranks as the stormiest year in the period to 2010 and is explained by exceptionally high cyclone counts for the region. The second and third wettest years in the IIP series (2002 and 2009 respectively) also rank highly in terms of storminess. Further similarities with Matthews et al. (2015) include 1915 being ranked as the stormiest winter and fourth wettest in the IIP series. Autumn 2000 ranks as the wettest for IIP and highest for cyclone counts. Spearman's rank correlation coefficients were derived for annual and seasonal IIP series and the corresponding NAO index (NAOI) (i.e. winter IIP and winter NAOI etc.). Statistically significant (0.05 level) but weak positive correlations are found for winter $(r=0.295)$, spring $(r=0.202)$ and autumn $(r=0.116)$. IIP summer precipitation is significantly and negatively correlated with summer NAOI $(r=-0.154)$. A positive but non-significant correlation is found between annual NAOI and annual IIP $(r=0.116)$.

Variability of trends within the IIP series was examined using a moving windows approach to assess trends across all possible start and end dates (minimum of 10 years). The resulting trends in seasonal precipitation for the IIP series are presented in Figure 10. For winter long records show positive trends; however, significant (0.05 level) trends 

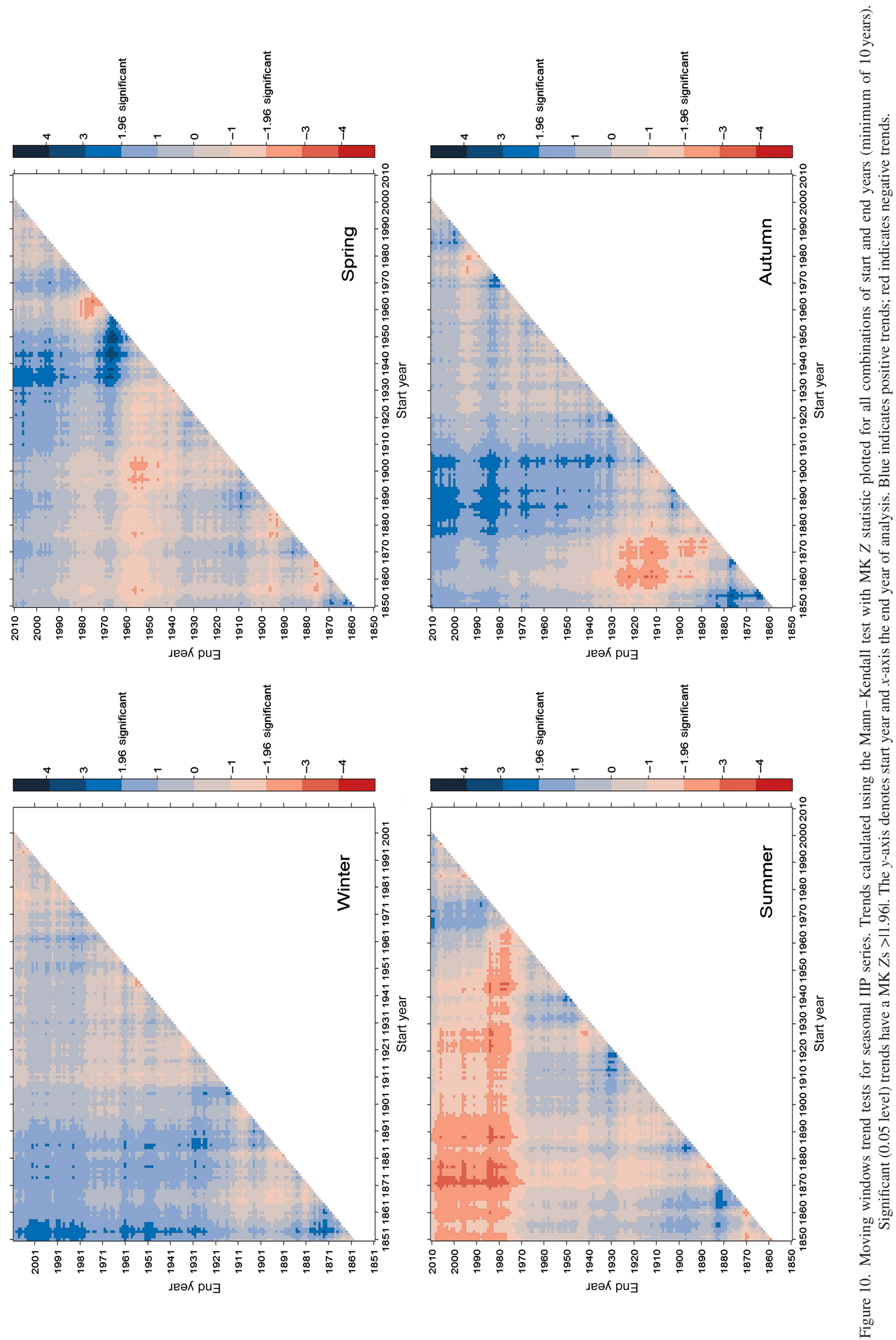
更 
are only associated with tests commencing before 1860 . As with station-based analyses, shorter records are not representative of longer term trends. For tests commencing after 1910 negative trends are evident for the winter IIP series. For spring, the complete record length shows weak positive trends with the direction and significance of trends dependent on period of analysis. Significant positive trends are found for tests commencing between 1930 and 1940. In summer, long records show significant (0.05 level) negative trends. These trends only become significant for tests ending after the 1970s. Again the period of record is critical with tests commencing after the 1970s showing positive trends. Finally, positive trends are found for all start years in autumn; however, significant trends are only returned for series commencing between 1880 and 1910 .

In summary, for both the IIP and individual station series there are few persistent trends evident with the magnitude, direction and significance of trends highly dependent on the period of record in all seasons due to strong inter-decadal variability. For the typical period of record available for digitized data, trends in winter and summer are not representative of results from longer records, while even shorter records commencing from the 1960s onwards show negative (positive) trends in winter and summer. Coherence in the temporal evolution of trends across all stations for both annual and seasonal indices increases confidence in the homogeneity of the network, as does the close correspondence with the EWP series and storminess indices of Matthews et al. (2015).

\section{Conclusions}

This research has produced an extended IIP archive for the period 1850-2010 using a suite of homogenization techniques. The resulting network, comprising 25 stations together with a composite series for the IoI, highlights the vital importance of long-term records in contextualizing climate variability and change. Regionally, the derived IIP series is second in longevity only to the EWP series, hence its addition to the research field offers rich opportunities to understand long-term variability at the scale of the BI - a sentinel maritime location on Europe's Atlantic coast. Correspondence between detected breaks and available metadata demonstrate the value of applying qualitative and quantitative techniques in parallel. Following homogenization and adjustment of detected breaks using HOMER, the assessment of variability and change over the period 1850-2010 indicates positive trends in winter and negative trends in summer precipitation. Trends in records covering the typical period of digitization (1941 onwards) were not always representative of trends since 1850 . Furthermore, results post-homogenization revealed changing magnitude and even direction of trends at some stations.

While cautionary flags are raised for some stations, confidence in the derived series is increased by collating metadata for each station, by coherence of trends across the network, by consistency with the EWP series (Alexander and Jones, 2001), by cyclone metrics derived for the BI (Matthews et al., 2015) and with the NAOI. For transparency we provide all available metadata as Appendix S1 and encourage this as standard practice in homogenization studies. In a stringent first test of the IIP network, Wilby et al. (2015) assess the occurrence and persistence of meteorological droughts in the IIP series. While suspicious drought persistence is identified for some stations, the IIP is found to provide a credible basis for stress testing water plans to extreme drought conditions thus increasing confidence in the dataset.

There is much scope for developing this initial work. Further stations could be added to the network by recovering additional hardcopy data from the archives and applying the methods adopted here. This would be particularly important for increasing confidence in the homogeneity of early parts of the record and for increasing confidence in break detection for stations with low correlations among reference networks. Future work could address spatial bias in the IIP network which is an artefact of the availability of long records.

Finally, our work shows the sense of advancing understanding of Irish climate on an all island basis using a network that could have wide utility in future research and in delivering improved baseline data for climate services. To this end the dataset produced here is freely available for use and download at www.met.ie/downloads/Long-Term-IIP-network.zip or by email with the corresponding author. As far as we are aware, this work represents the first application of HOMER to a long-term precipitation network and bodes well for use in other regions.

\section{Acknowledgements}

We thank Met Éireann for access to archived records and provision of digitized data. Met Éireann librarian Mairéad Traynor provided help and advice with archive records and transcription. Thanks are also extended to Mary Curley for advice and support in applying HOMER and to Prof. Phil Jones for advice and insight on early work and updates in constructing the CRU dataset. Mark Bailey and Prof. John Butler at Armagh Observatory gave data and advice on Armagh records. Shaun Harrigan offered valuable feedback on previous drafts. SN was funded by the Irish Research Council. CM/TM and JC/SW acknowledge funding provided by the Irish Environmental Protection Agency under projects 2014-CCRP-MS.16 and 2012-CCRP-FS.11, respectively.

\section{Supporting Information}

The following supporting information is available as part of the online article:

Appendix S1. Station bridging and network metadata.

\section{References}

Alexander LV, Jones PD. 2001. Updated precipitation series for the UK and discussion of recent extremes. Atmos. Sci. Lett. 1: 142-150. 
Alexandersson H, Moberg A. 1997. Homogenisation of Swedish temperature data. 1. Homogeneity test for linear trends. Int. J. Climatol. 17: $25-34$.

Auer I, Böhm R, Jurković A, Orlik A, Potzmann R, Schöner W, Ungersböck M, Brunetti M, Nanni T, Maugeri M, Briffa K, Jones P, Efthymiadis D, Mestre O, Moisselin M, Begert M, Brazdil R, Bochnicek O, Cegnar T, Gajić-Čapka M, Zaninović K, Majstorović Z, Szalai S, Szentimery T, Mercalli L. 2005. A new instrumental precipitation dataset for the Greater Alpine Region for the period 1800-2002. Int. J. Climatol. 25(2): 139-166.

Barker PA, Wilby RL, Borrows J. 2004. A 200-year precipitation index for the central English Lake District. Hydrol. Sci. J. 49: 769-785.

Briffa KR. 1984. Tree-Climate Relationships and Dendroclimatic Reconstruction in the British Isles. Unpublished $\mathrm{PhD}$ dissertation, University of East Anglia, Norwich, UK.

Burt TP, Adamson JK, Lane AMJ. 1998. Long term rainfall and stream flow records for north central England: putting the environmental Change Network site at Moor House, Upper Teesdale, in context. Hydrol. Sci. J. 43(5): 775-787.

Burt TP, Jones PD, Howden NJK. 2014. An analysis of rainfall across the British Isles in the 1870s. Int. J. Climatol. 35: 2934-2947, doi: $10.1002 /$ joc. 4184 .

Butler CJ, Coughlin ADS, Fee DT. 1998. Precipitation at Armagh Observatory 1838-1997. Biol. Environ. 98B(2): 123-140.

Cao LJ, Yan ZW. 2012. Progress in research on homogenization of climate data. Adv. Clim. Change Res. 3(2): 59-67.

Caussinus H, Lyazrhi F. 1997. Choosing a linear model with a random number of change-points and outliers. Ann. Inst. Statist. Math. 49: $761-775$

Caussinus H, Mestre O. 2004. Detection and correction of artificial shifts in climate series. Appl. Stat. 53: 405-425.

Coll J, Curley C, Walsh S, Sweeney J. 2014. Ireland with HOMER. In Proceedings of the 8th Seminar for Homogenisation and Ouality Control in Climatological Databases and 3rd Conference on Spatial Interpolation in Climatology and Meteorology, Climate Data and Monitoring WCDMP-No. 84, WMO, Geneva, 23-45.

Coll J, Curley C, Domonkos P, Aguilar E, Walsh S, Sweeney J. 2015. An application of HOMER and ACMANT for homogenising monthly precipitation records in Ireland. Geophys. Res. Abstr. 17: EGU2015-EGU15502.

De Jongh ILM, Verhoest NEC, De Troch FP. 2006. Analysis of 105-year time series of precipitation observed at Uccle, Belgium. Int. J. Climatol. 26: 2023-2039.

Della-Marta PM, Wanner H. 2006. A method for homogenising the extremes and mean of daily temperature measurements. J. Clim. 19: 4179-4197.

Domonkos P. 2011. Homogenising time series: beliefs, dogmas and facts. Adv. Sci. Res. 6: $167-172$

Domonkos P. 2014. Homogenisation of precipitation time series with ACMANT. Theor. Appl. Climatol. 118: 1-2.

Domonkos P, Poza R, Efthymiadis D. 2011. Newest developments of ACMANT. Adv. Sci. Res. 6: 7-11.

Dwyer N. 2012. The status of Ireland's climate. Environmental Protection Agency, Johnstown Castle. Co. Wexford, Ireland, 14-16.

Freitas L, Pereira MG, Caramelo L, Mendes M, Nunes LF. 2013. Homogeneity of monthly air temperature in Portugal with HOMER and MASH. Idojaras 117(1): 69-90.

Gregory JM, Jones PD, Wigley TML. 1991. Precipitation in Britain: an analysis of area-average data updated to 1989. Int. J. Climatol. 11: $331-345$.

Guijarro JA. 2011. Climatol Version 2.0, An $R$ Contributed Package for Homogenisation of Climatological Series. State Meteorological Agency, Balearic Islands Office: Palermo, Spain.

Hawkins DM. 2001. Fitting multiple change-point models to data. Comput. Stat. Data Anal. 37: 323-341.

HOME. 2013. Homepage of the COST Action ES0601 - Advances in Homogenisation Methods of Climate Series: An Integrated Approach (HOME). http://www.homogenisation.org (accessed 21 September 2015).

Jones PD. 1983. Further composite rainfall records for the United Kingdom. Meteorol. Mag. 112: 19-27.

Jones PD. 1984. River flow reconstruction from precipitation data. J. Climatol. 4: 171-186.

Jones P, Conway D. 1997. Precipitation in the British Isles: an analysis of area-average data updated to 1995. Int. J. Climatol. 17: 427-438.

Jones PD, Lister DH, Wilby RL, Kostopoulou E. 2006. Extended riverflow reconstructions for England and Wales, 1865-2002. Int. J. Climatol. 26: 219-231.
Kendall MG. 1975. Rank Correlation Methods, 4th edn. Charles Griffin: London.

Kiely G. 1999. Climate change in Ireland from precipitation and streamflow observations. Adv. Water Resour. 23: 141-151.

Kuglitsch FG, Toreti A, Xoplaki E, Della-Marta PM, Luterbacher J, Wanner H. 2009. Homogenisation of daily maximum temperature series in the Mediterranean. J. Geophys. Res. 114: 1-6.

Leahy PG, Kiely G. 2011. Short duration rainfall extremes in Ireland: influence of climatic variability. Water Resour. Manage. 25: 987-1003

Mamara A, Argirio AA, Anadranistakis M. 2014. Detection and correction of inhomogeneities in Greek climate temperature series. Int. J. Climatol. 34: 3024-3043.

Matthews T, Murphy C, Wilby RL, Harrigan S. 2015. A cyclone climatology of the British-Irish Isles 1871-2012. Int. J. Climatol., doi: $10.1002 /$ joc. 4425 .

McElwain L, Sweeney J. 2007. Key Meteorological Indicators of Climate Change in Ireland. Environmental Protection Agency, Johnstown Castle Estate: Wexford, Ireland, $31 \mathrm{pp}$.

Menne MJ, Williams CN. 2005. Detection of undocumented changepoints using multiple test statistics and composite reference series. J. Clim. 18(20): 4271-4286.

Mestre O, Domonkos P, Picard F, Auer I, Robin S, Lebarbier E, Böhm R, Aguilar E, Guikarro J, Vertachnik G, Klan-car M, Dubuisson B Stepanek P. 2013. HOMER: a homogenization software - methods and applications. Idojaras 117(1): 47-67.

Moberg A, Jones PD, Lister D, Walther A, Brunet M, Jacobeit J, Alexander LV, Della-Marta PM, Luterbacher J, Yiou P, Chen D, Klein Tank AMG, Saladié O, Sigró J, Aguilar E, Alexandersson H, Almarza C, Auer I, Barriendos M, Begert M, Bergström H, Böhm R, Butler CJ, Caesar J, Drebs A, Founda D, Gerstengarbe F-W, Micela G, Maugeri M, Österle H, Pandzic K, Petrakis M, Srnec L, Tolasz R, Tuomenvirta H, Werner PC, Linderholm H, Philipp A, Wanner H, Xoplaki E. 2006. Indices for daily temperature and precipitation extremes in Europe analyzed for the period 1901-2000. J. Geophys. Res. 111: D22106.

Moisselin JM, Canellas C. 2005. Longues series d'insolation homogeneisees en France. C. R. Geosci. 337(8): 729-734.

Murphy C, Harrigan S, Hall J, Wilby RL. 2013. Climate driven trends in mean and high flows from a network of reference stations in Ireland Hydrol. Sci. J. 58: 755-772.

Peterson TC, Easterling DR, Karl TR, Groisman P, Nicholls N, Plummer N, Torok S, Auer I, Boehm R, Gullett D, Vincent L, Heino R, Tuomenvirta H, Mestre O, Szentimrey T, Salinger J, Førland EJ, Hanssen-Bauer I, Alexandersson H, Jones P, Parker D. 1998. Homogeneity adjustments of in situ atmospheric climate data: a review. Int J. Climatol 18: 1493-1517.

Pettitt AN. 1979. A non-parametric approach to the change-point problem. J. R. Stat. Soc. C 28: 126-135.

Picard F, Lebarbier E, Hoebeke M, Rigaill G, Thiam B, Robin S. 2011. Joint segmentation, calling and normalization of multiple CGH profiles. Biostatistics 12: 413-428.

Scheifinger H, Böhm R, Auer I. 2003. Räumliche Dekorrelation von Klimazeitreihen unterschiedlicher zeitlicher Auflösung und ihre Bedeutung für ihre Homogenisierbarkeit und die Repräsentativität von Ergebnissen. 6. Deutsche Klimatagung, Klimavariabilität 7 2003, 22-25, September 2003, Potsdam. Terra Nostra, Schriftenreihe der AlfredWegener-Stiftung 2003/6, 375-379.

Sheridan T. 2001. Analysis of trends at some Irish rainfall stations. Me Eireann Technical Report, Met Éireann, Glasnevin Hill, Dublin 9 , Ireland.

Štěpánek P, Mikulová K. 2008. Homogenisation of air temperature and relative humidity monthly means of individual observation hours in the area of the Czech and Slovak Republic. In 5th Seminar for Homogenisation and Quality Control in Climatological Databases, Hungarian Meteorological Service, Budapest, $147-163$.

Tabony RC. 1980. A set of homogeneous European rainfall series Meteorological 13 Branch Memorandum No. 104, Meteorological Office, Bracknell, UK

Todd B, MacDonald N, Chiverrell RC. 2014. Revision and extension of the composite Carlisle rainfall record, northwest England: 1757-2012. Int. J. Climatol., doi: 10.1002/joc.4233.

Toreti FG, Kuglitsch A, Xoplaki E, Luterbacher J. 2012. A novel approach for the detection of inhomogeneities affecting climate time series. J. Appl. Meteorol. Climatol. 51(2): 317-326.

Venema V, Mestre O, Aguilar E, Auer I, Guijarro JA, Domonkos P, Vertacnik G, Szentimrey T, Stepanek P, Zahradnicek P, Viarre J, 
Müller-Westermeier G, Lakatos M, Williams CN, Menne M, Lindau R, Rasol D, Rustemeier E, Kolokythas K, Marinova T, Andresen L, Acquaotta F, Fratianni S, Cheval S, Klancar M, Brunetti M, Gruber CH, Prohom Duran M, Likso T, Esteban P, Brandsma T. 2012. Benchmarking homogenization algorithms for monthly data. Clim. Past 8: 89-115.

Vertačnik G, Dolinar M, Bertalanič R, Klančar M, Dvoršek D, Nadbath M. 2015. Ensemble homogenization of Slovenian monthly air temperature series. Int. J. Climatol., doi: 10.1002/joc.4265.

Wang S, McGrath R, Semmler T, Sweeney C. 2006. Validation of simulated precipitation patterns over Ireland for the period 1961-2000 Int. J. Climatol. 26: 251-266.

Wijngaard JB, Klein Tank AMG, Konnen GP. 2003. Homogeneity of 20th century European daily temperature and precipitation series. Int. J. Climatol. 23: 679-692.
Wilby R. 2006. When and where might climate change be detectable in UK river flows? Geophys. Res. Lett. 33: L19407.

Wilby RL, Quinn NW. 2013. Reconstructing multi-decadal variations in fluvial flood risk using atmospheric circulation patterns. J. Hydrol. 487: $109-121$.

Wilby RL, Noone S, Murphy C, Matthews T, Harrigan S, Broderick C. 2015. An evaluation of persistent meteorological drought using a homogeneous Island of Ireland precipitation network. Int. J. Climatol., (in press).

World Meteorological Organisation. 2011. Guide to Climatological Practices (WMO/No 100). World Meteorological Organisation: Geneva, Switzerland.

Zhang XB, Vincent LA, Hogg WD, Niitsoo A. 2001. Temperature and precipitation trends in Canada during the 20th century. Atmos. Ocean 38: $395-429$. 